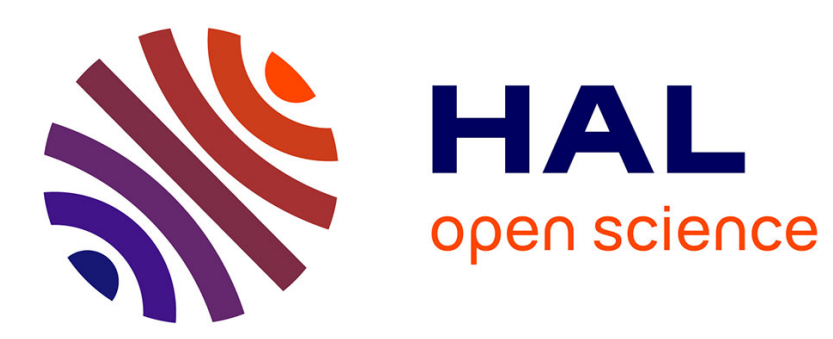

\title{
Competition between capillary and gravity forces in a viscous liquid film heated by a Gaussian laser beam \\ Germán da Costa
}

\section{To cite this version:}

Germán da Costa. Competition between capillary and gravity forces in a viscous liquid film heated by a Gaussian laser beam. Journal de Physique, 1982, 43 (10), pp.1503-1508. 10.1051/jphys:0198200430100150300 . jpa-00209532

\section{HAL Id: jpa-00209532 https://hal.science/jpa-00209532}

Submitted on 1 Jan 1982

HAL is a multi-disciplinary open access archive for the deposit and dissemination of scientific research documents, whether they are published or not. The documents may come from teaching and research institutions in France or abroad, or from public or private research centers.
L'archive ouverte pluridisciplinaire HAL, est destinée au dépôt et à la diffusion de documents scientifiques de niveau recherche, publiés ou non, émanant des établissements d'enseignement et de recherche français ou étrangers, des laboratoires publics ou privés. 


\title{
Competition between capillary and gravity forces in a viscous liquid film heated by a Gaussian laser beam
}

\author{
G. Da Costa $(*)$ \\ Laboratoire d'Optique, U.E.R. des Sciences, Université de Limoges, 123, rue Albert Thomas, 87060 Limoges Cedex, \\ France
}

(Reçu le 11 février 1982, révisé le 18 mai, accepté le 7 juin 1982)

\begin{abstract}
Résumé. - La surface libre d'un échantillon liquide (huile lourde) est chauffée au moyen d'un faisceau laser Gaussien. On présente des enregistrements photographiques de la forme de la surface et de la distribution des vitesses. La surface passe par une étape initiale de dilatation, suivie de la formation d'une dépression. Une interprétation théorique en est donnée dans le cadre de solutions stationnaires de l'équation de Navier-Stokes, considérant la dépendance de la masse volumique et de la tension superficielle vis-à-vis de la température. On prouve que le signe des variations de la hauteur de la surface dans la région chaude dépend de façon critique des paramètres expérimentaux. Les expériences et les résultats théoriques montrent que le phénomène est dû à la compétition entre les variations de la masse volumique et de la tension superficielle.
\end{abstract}

\begin{abstract}
The free-surface of a liquid sample (heavy oil) is locally heated by irradiation with a Gaussian laser beam. Photographic records of the surface profile and flow pattern are presented. The free-surface passes by an earlier dilatation stage, followed by the formation of a pit in the top of the expanded region. A theoretical analysis based on the stationary solution of Navier-Stokes equation with temperature-dependent density and surfacetension is made. It is shown that the sign of the surface-height variations in the hot region depends critically on the values of the dimensionless quantities characterizing the experiment. The surface profile and the velocity distribution are calculated and compared with the experimental results. We conclude that the phenomena observed are due to competition between the density- and surface-tension gradients.
\end{abstract}

1. Introduction. - In classical Bénard's studies of the convective instability [1] the bottom of the liquid sample was heated at a constant and uniform temperature, while the upper surface is in free contact with the ambient air. Bénard found that the surface was depressed at the hotter areas, near the points of upwelling flow. However, other authors [2] observed later an opposite structure (that is, an elevation of the hotter regions) when the sample material is changed while keeping the same experimental setup. It was suggested [3] that the concavity of the surface may be determined by the competition between surfacetension and buoyancy-driven flows, and that the predominancy of one or the other mechanism may be critically related to the depth of the vessel. In our experiments (Fig. 1a) the temperature gradient is imposed by heating the samples with a constantpower Gaussian laser beam. A theoretical analysis

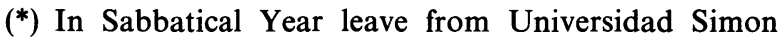
Bolivar, Caracas, Venezuela. based on the steady-state solution of Navier-Stokes equation for a liquid film with temperature-dependent density and surface-tension is presented in section 2 of the actual paper. The corresponding experiments are described in section 3 .

2. Theoretical calculation of the surface shape and velocity distribution. - The temperature distribution in a thin sample heated by a Gaussian laser beam is [4] :

$$
T-T_{0}=T_{\mathrm{c}} f(\beta, \gamma)=T_{\mathrm{c}} \int_{\frac{\beta^{2}}{1+\gamma}}^{\beta^{2}} \frac{\mathrm{d} \theta}{\theta \exp \theta}
$$

where $\beta=x / a, \gamma=t / t_{0}, t$ is the heating time, $t_{0}=a^{2} / 4 \kappa$ is the thermal time-constant, $\kappa$ is the thermal diffusivity, $k$ is the thermal conductivity, $z_{0}$ is the initial height of the liquid surface,

$$
Q(\beta)=Q_{0} \cdot \exp \left(-\beta^{2}\right)
$$

is the power absorbed by the sample per unit area, and $T_{\mathrm{c}}=Q_{0} a^{2} / 4 k z_{0}$ is a characteristic temperature 


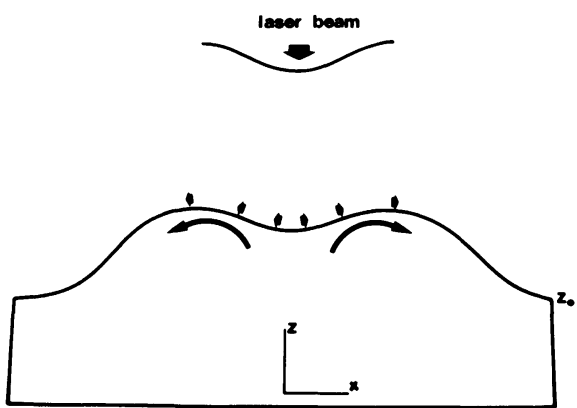

a

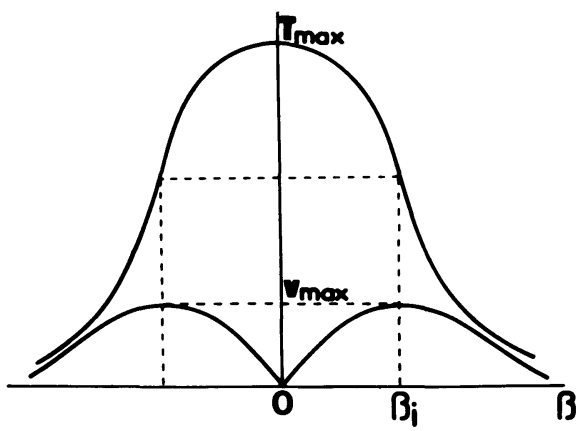

b

Fig. 1. - a) A liquid film (initial depth $z_{0}$ ) contained in a thermally-insulating vessel is heated by a Gaussian laser beam at the free-surface. This produces a time-growing, radially-decreasing temperature distribution. $b$ ) The upper curve represents the dimensionless temperature distribution $f(\beta, \gamma)$ at an arbitrary time-instant. The lower curve depicts at an arbitrary scale the derivative $\partial f / \partial \beta$, which is in turn an approximate expression for the velocity distribution in the free-surface. $\beta_{\mathrm{i}}$ is the inflexion point of the temperature distribution, where the surface-tension gradient is a maximum.

of the material. The dimensionless temperature $f(\beta, \gamma)$ is sketched in figure $1 b$ (upper curve) at an arbitrary time-instant. The hotter point is placed at $\beta=0$, where $f(0, \gamma)=\ln (1+\gamma)$. This temperature distribution induces in turn density- and surface-tension distributions $\rho(T), \alpha(T)$ :

$$
\rho=\rho_{0}+d_{0}\left(T-T_{0}\right)=\rho_{0}+\left(\frac{\partial \rho}{\partial T}\right)_{T=T_{0}}\left(T-T_{0}\right)
$$

$$
\alpha=\alpha_{0}+c_{0}\left(T-T_{0}\right)=\alpha_{0}+\left(\frac{\partial \alpha}{\partial T}\right)_{T=T_{0}}\left(T-T_{0}\right) .
$$

These are, of course, first-order approximations. The quantities $\left(\rho_{0}, \alpha_{0}\right)$ are the initial values of $(\rho, \alpha)$ at $t=0$. The derivatives $\left(d_{0}, c_{0}\right)$ of $(\rho, \alpha)$ with respect to the temperature are in general negative quantities. As a result of competition between the density- and surface-tension variations the free-surface adopts the profile given by [5] :

$$
u=\frac{z_{\mathrm{s}}}{z_{0}}=\left[\left(\frac{\rho_{0}}{\rho}\right)^{3 / 4}+\frac{3}{\rho g z_{0}^{2}}\left(\alpha-\alpha_{0}\right)\right]^{1 / 2} .
$$

Substitution of equation (1) into equations $(2 a-b)$ and then into equation (3) yields :

$$
u=\left[w^{3 / 4}-\Omega(w-1)\right]^{1 / 2}
$$

with :

$$
\begin{aligned}
& w=\frac{1}{1+D f(\beta, \gamma)}, \quad D=\frac{d_{0} T_{\mathrm{c}}}{\rho_{0}} \\
& A=\frac{c_{0} T_{\mathrm{c}}}{\rho_{0} g z_{0}^{2}}, \quad \Omega=\frac{3 A}{D}=\frac{3 c_{0}}{g z_{0}^{2} d_{0}} .
\end{aligned}
$$

$z_{\mathrm{s}}$ is the local surface-height at the point where the density is $\rho$ and the surface tension is $\alpha$. It may be noticed that in this model $(\rho, \alpha)$ are functions only of the spatial coordinate $x$ and of the time $t$. Equation (4) gives then the surface profile $z_{\mathrm{s}}(x)$ with the time $t$ as a parameter. We are reminded also from reference [5] that equation (3) is valid only in the stationary stage of the experiment $(\partial v / \partial t \simeq 0$ in NavierStokes equation, $v$ being the velocity of the liquid). It will be shown later (Section 4) that the duration of the initial transient stage where $\partial v / \partial t$ cannot be neglected is much smaller than the temporal-resolution of our experimental setup. This is due to the high values of the viscosity of our samples, which provides a strong damping of the transient terms of the solution.

The temporal evolution of a given surface-point ( $\beta=$ constant) is studied by calculating $\partial u / \partial \gamma$, which vanishes only at $w=w_{\mathrm{M}}=(3 / 4 \Omega)^{4}$. It is easily seen that the function $w(\beta, \gamma)$ has the properties $w(\beta, 0)=1$ and $w(\beta, \gamma) \geqslant 1$. As a result, if $\Omega \geqslant 3 / 4$ one has $w_{\mathrm{M}} \leqslant 1$ and $\partial u / \partial \gamma \leqslant 0$ for any value of $(\beta, \gamma)$. This means that the surface-height at any point $\beta=$ constant is a decreasing function of time : only a pit is formed in the hot region at any time-instant. This coincides with the behaviour observed by Bénard [1]. If on the contrary one has $\Omega<3 / 4$ (and consequently $w_{M}>1$ ) the surface-height at any given point increases first for small heating-times, until it passes by a maximum at the time-instant determined by $w=w_{\mathrm{M}}$. At this time-instant one has also :

$$
f(\beta, \gamma)=\frac{1}{D}\left(\frac{1}{w_{\mathrm{M}}}-1\right)=f_{\mathrm{M}} .
$$

The first point to attain this condition is the central hot-point, where $f(0, \gamma)=\ln (1+\gamma)$. So the surfaceheight at this point attains a maximum value at the time-instant $\gamma_{0}$ determined by $\ln (1+\gamma)=f_{\mathrm{M}}$, or :

$$
\gamma_{0}=\exp \left(f_{\mathrm{M}}\right)-1 \text {. }
$$


For greater heating-times $\left(\gamma>\gamma_{0}\right)$ the surface-height at the central hot-point becomes a decreasing function of time, while the same phenomenon takes place at surface-points with increasingly larger values of the abscissa $\beta$. In other words, two symmetrical maxima of the surface-height travel outwards from the central hot-point. The phenomenon may also be described as an initial dilatation followed by the formation of a pit in the top of the dilated region. As an example, the function $f(\beta, \gamma)$ is approximated by

$$
f(\beta, \gamma)=\gamma \exp \left(-\beta^{2}\right)
$$

for small heating-times $t \ll t_{0}$, and the dimensionless quantities are chosen by trial and error in order to fit the experimental results of section 3 (Fig. 3). The numerically calculated results (corresponding to $\Omega=0.69$ ) are presented in figure 2 . The splitting of the surface takes place at $t=11 \mathrm{~s}$.

The velocity distribution is calculated now. From reference [5] we have :

$\eta \cdot v=g z\left(z_{\mathrm{s}}-\frac{z}{2}\right) \frac{\partial\left(\rho z_{\mathrm{s}}\right)}{\partial x}-\frac{g z}{6}\left(3 z_{\mathrm{s}}^{2}-z^{2}\right) \frac{\partial \rho}{\partial x}-z \frac{\partial \alpha}{\partial x}$

where $\eta$ is the viscosity, $v(x, z)$ is the $x$-component of the velocity at a point with coordinates $(x, z)$ and $z_{\mathrm{s}}(x)$ is (as in the preceding section) the free-surface height. By substitution of equations (2-4) into equation (8) one arrives at :

$$
\begin{array}{r}
\frac{v}{v_{0}}=\left(\frac{\partial f}{\partial \beta}\right) \cdot h\left[\left(\frac{h}{2}-u\right) \frac{D v}{2 u}\left(\frac{3}{4} w^{-1 / 4}-\Omega\right)+\right. \\
\left.+D\left(-\frac{h^{2}}{6}+\frac{u^{2}}{2}-\frac{u h}{2}\right)-A\right]
\end{array}
$$

with $h=z / z_{0}$ and $v_{0}=g z_{0}^{3} \rho_{0} / a \eta$. The complete study of the resulting flow pattern is out of the scope of this
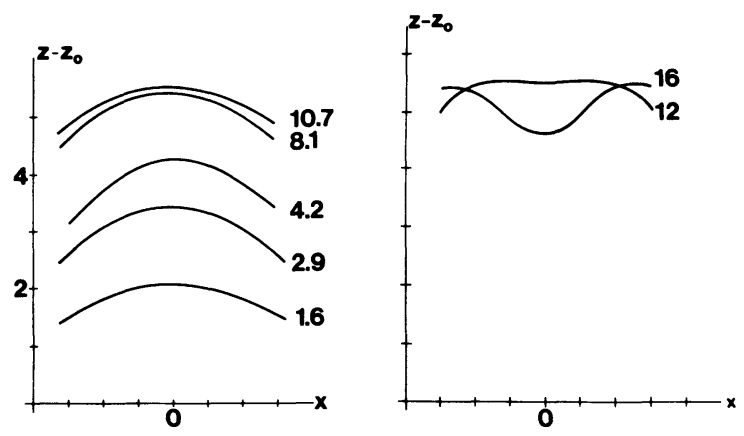

Fig. 2. - Surface profiles calculated from equation (4) with $\Omega=0.69$. The point 0 corresponds to the central hot-point. Each horizontal division corresponds to $0.2 \mathrm{~mm}$. The height increase $\left(z-z_{0}\right)$ is measured in microns. The quantities beside each curve are the time-intervals elapsed from the beginning of irradiation, measured in seconds. These numerical calculations are to be compared with the experimental results of figure 3 . The heating time necessary for the surface to attain its maximum height at $x=0$ is $t=11 \mathrm{~s}$.
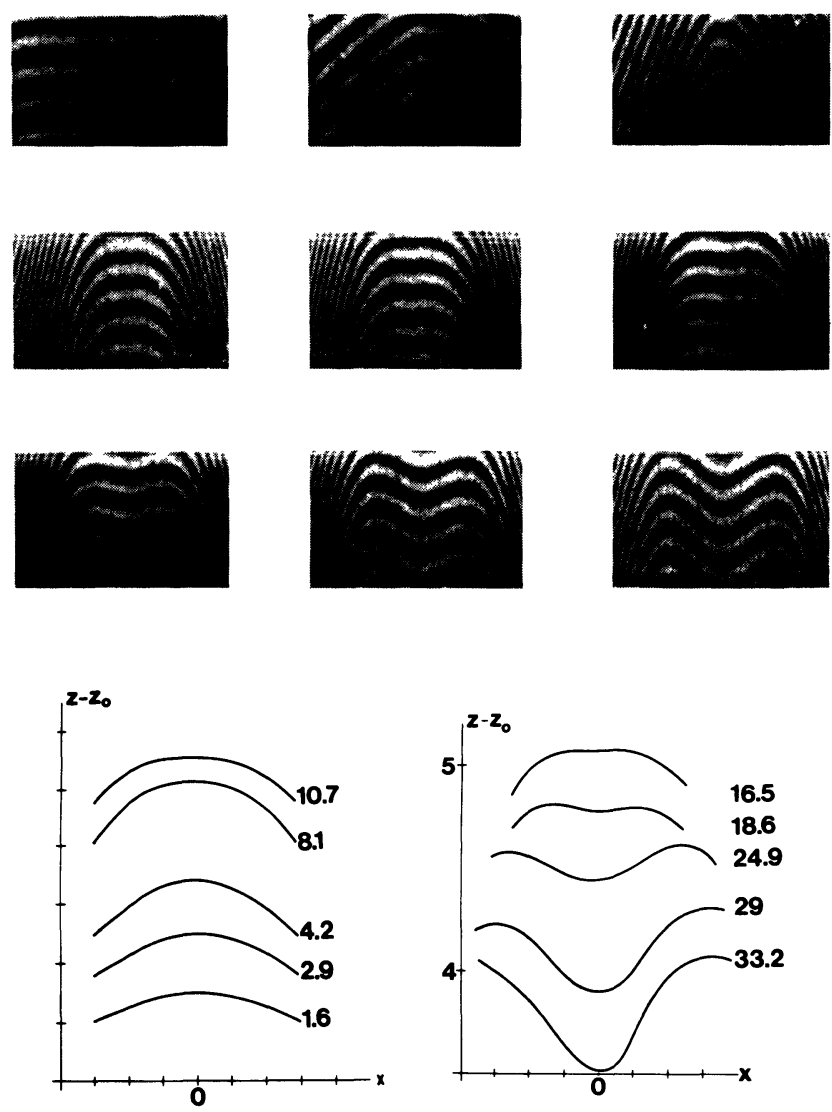

Fig. 3. - Interferometric records of the surface profile of a heavy oil heated by a Gaussian laser beam. The sequence runs from left to right and from up to down. The time-interval between two successive photographs is about $3 \mathrm{~s}$. The total width corresponding to each photograph is $3 \mathrm{~mm}$. The surface profile measured from these photographs is plotted in the graphs at the bottom of the picture. The point 0 corresponds to the central hot-point. Each horizontal division represents $0.2 \mathrm{~mm}$. Each vertical division represents a height-increase of $10^{-3} \mathrm{~mm}$.

paper. It is noted however that the velocity distribution is strongly influenced by the term $\partial f / \partial \beta$, which is sketched in figure $1 b$ (lower curve).

3. Experimental determination of the surface shape and velocity distribution. - The experiment is schematized in figure $1 a$. The radiant source is an argon laser at $\lambda=4880 \AA$. The beam diameter is $2 a=2 \mathrm{~mm}$ and the beam power is $35 \mathrm{~mW}$. The samples are heavy oils from the Orinoco Belt (Venezuela). The density is $\rho \cong 1 \mathrm{~g} / \mathrm{cm}^{3}$. The viscosity is $\eta \simeq 10$ poise at $25^{\circ} \mathrm{C}$ and 0.1 poise at $50{ }^{\circ} \mathrm{C}$. The thermal-conduction timeconstant is $t_{0}=1 \mathrm{~s}$. The samples absorb more than $99 \%$ of the incident beam. This allows one to obtain relatively large temperature differences (about $5^{\circ} \mathrm{C}$ ) and height variations. On the other hand, it is impossible to study the velocity distribution in the bulk by optical methods (such as laser Doppler anemometry) for the sample is not transparent to visible radiation. 
The interferometric records of figure 3 display the temporal evolution of a meridian section of the surface after the beginning of heating at $t=0$. A review of optical methods applied to this kind of experiments is made in reference [6]. The interferometric techniques used to obtain the photographs of figures 3-4 are described in reference [7].

All the curves in each photograph of figure 3 correspond to the same meridian section of the surface. The surface profiles measured from these photographs are presented in the graphs at the bottom of the picture : they are in good agreement with the theoretical results of figure 2 .

Another interferometric technique [7] allows one to record the equal-height curves of the surface. The results are shown in figure 4 . The elliptical shape of the upper pit is due to oblique incidence of the laser beam.

For long heating times the pit tends asymptotically to a stable shape, the maximum depth being about $0.1 \mathrm{~mm}$. Small bubbles get out from the central hotpoint and travel radially, drawn by the centrifugal surface-tension gradient. Their images appear in the light field reflected from the pit (Fig. 5). The speed of a typical bubble is measured as a function of $\beta=x / a$ and represented in figure $6 a$. A pictorial representation of the whole flow pattern is shown in figure $6 b$.

4. Conclusions and additional remarks. $-a$ ) The temporal evolution of the surface profile shown in figures 3-4 agrees fairly well with the theoretical predictions in the case $\Omega<3 / 4$. The surface expands in the hotter area in the initial heating stage. The vertical speed at the central hot point is about $10^{-3} \mathrm{~mm} / \mathrm{s}$ at a heating power of $35 \mathrm{~mW}$. About $11 \mathrm{~s}$ after the beginning of irradiation the surface splits in the top of the expanded region.

b) The dimensionless quantities that determine the evolution of the surface profile are $D=d_{0} T_{\mathrm{c}} / \rho_{0}$ and $\Omega=3 c_{0} / g z_{0}^{2} d_{0}$. There exist a drastic change in the behaviour of the system at $\Omega=3 / 4$. So the phenomenon is ruled by the competition between the surface-tension and the density variations $\left(c_{0}, d_{0}\right)$.The critical depth (whose existence was proposed in Ref. [3]) is $z_{0 c}=4 c_{0} / g d_{0}$. We do not dispose of experimental values of $\left(c_{0}, d_{0}\right)$ for our samples. The ratio $c_{0} / d_{0}$ is, indeed, strongly dependent on the temperature. For example, for water at $20^{\circ} \mathrm{C}$ one has

$$
c_{0} / d_{0}=750 \mathrm{~cm}^{3} / \mathrm{s}^{2}
$$

and $c_{0} / d_{0}=500 \mathrm{~cm}^{3} / \mathrm{s}^{2}$ at $30^{\circ} \mathrm{C}$. These variations may be the reason for the contradictory results obtained by different authors $[1,2]$ in experiments involving temperature inhomogeneities.

c) The approximate expression of the velocity distribution sketched in figure $1 b$ predicts a radial flow pattern with its centre in the hot-point at the sample surface. The speed is an increasing function of the radial position for $\beta<\beta_{\mathrm{i}}$. These predictions are in good
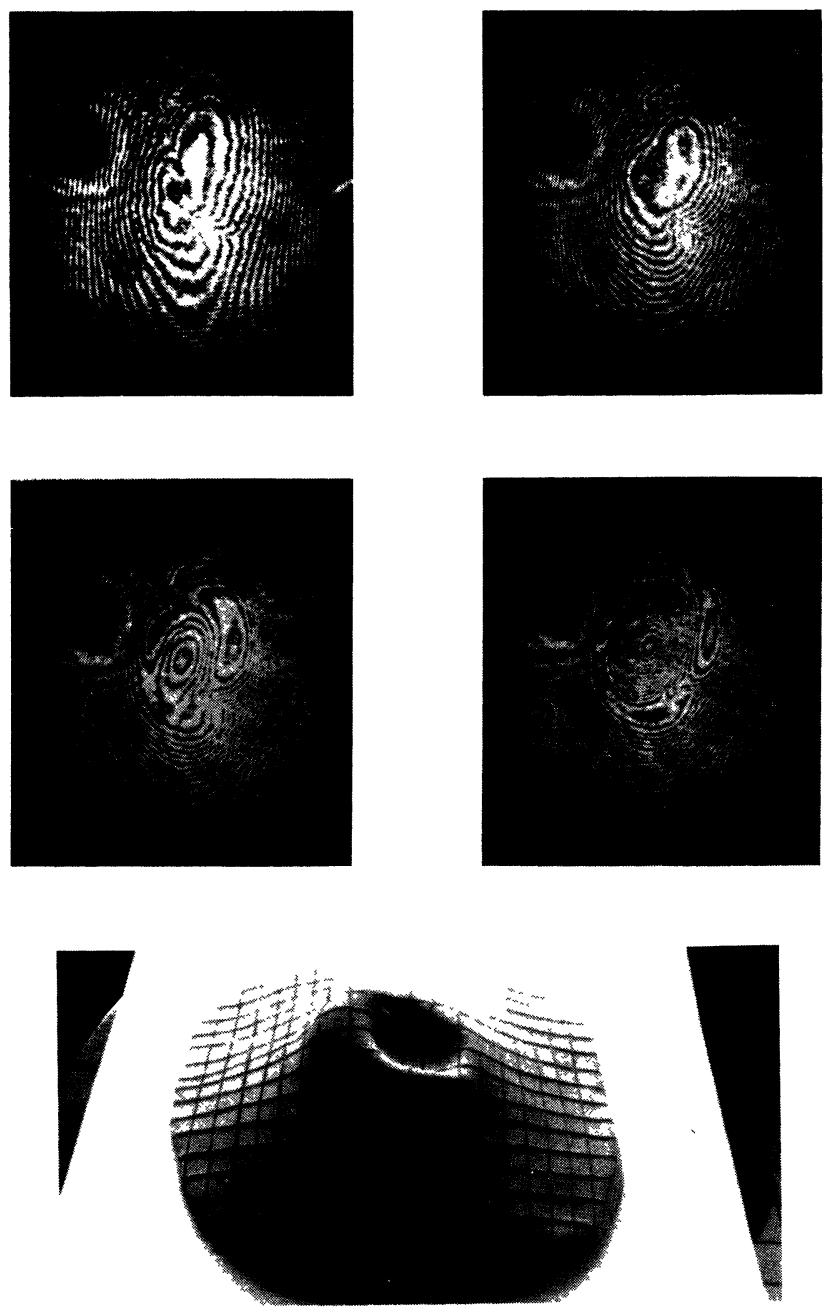

Fig. 4. - Equal-height curves of the surface of a heavy oil heated by a laser beam in oblique incidence. The heightdifference corresponding to two adjacent (dark-white) fringes is $1582 \AA$. The first photograph corresponds to the earlier dilatation stage. In the second one, the upper plateau is already formed. The additional fringe-system appearing in the centre of the next two photographs corresponds to the formation of the pit. The clay model represents the surface shape at the final stage.

qualitative agreement with the experimental results of section 3. However, a complete analysis of equation (9) is still lacking. The typical velocity of the phenomenon is $v_{0}=g z_{0}^{3} \rho_{0} / a \eta$. For our heavy oils at $25^{\circ} \mathrm{C}$ one has $\rho \cong 1 \mathrm{~g} / \mathrm{cm}^{3}, \quad \eta \cong 10$ poise, so that $v_{0} \cong 1 \mathrm{~mm} / \mathrm{s}$.

d) The integration of Navier-Stokes equation performed in reference [5] is valid only in the stationary stage of the experiment. A dynamical time-constant of the experiment is $\tau=\rho_{0} z_{0}^{2} / \eta$, and the thermal timeconstant is $t_{0}=a^{2} / 4 \kappa$. While for water one has $\tau \cong t_{0} \cong 1 \mathrm{~s}$, for heavy oils at $25^{\circ} \mathrm{C}$ the thermal timeconstant is approximately the same but the dynamical time-constant is $10^{3}$ times smaller. This supports utilization of the stationary solution to explain our experimental results. However, this is not a rigorous 

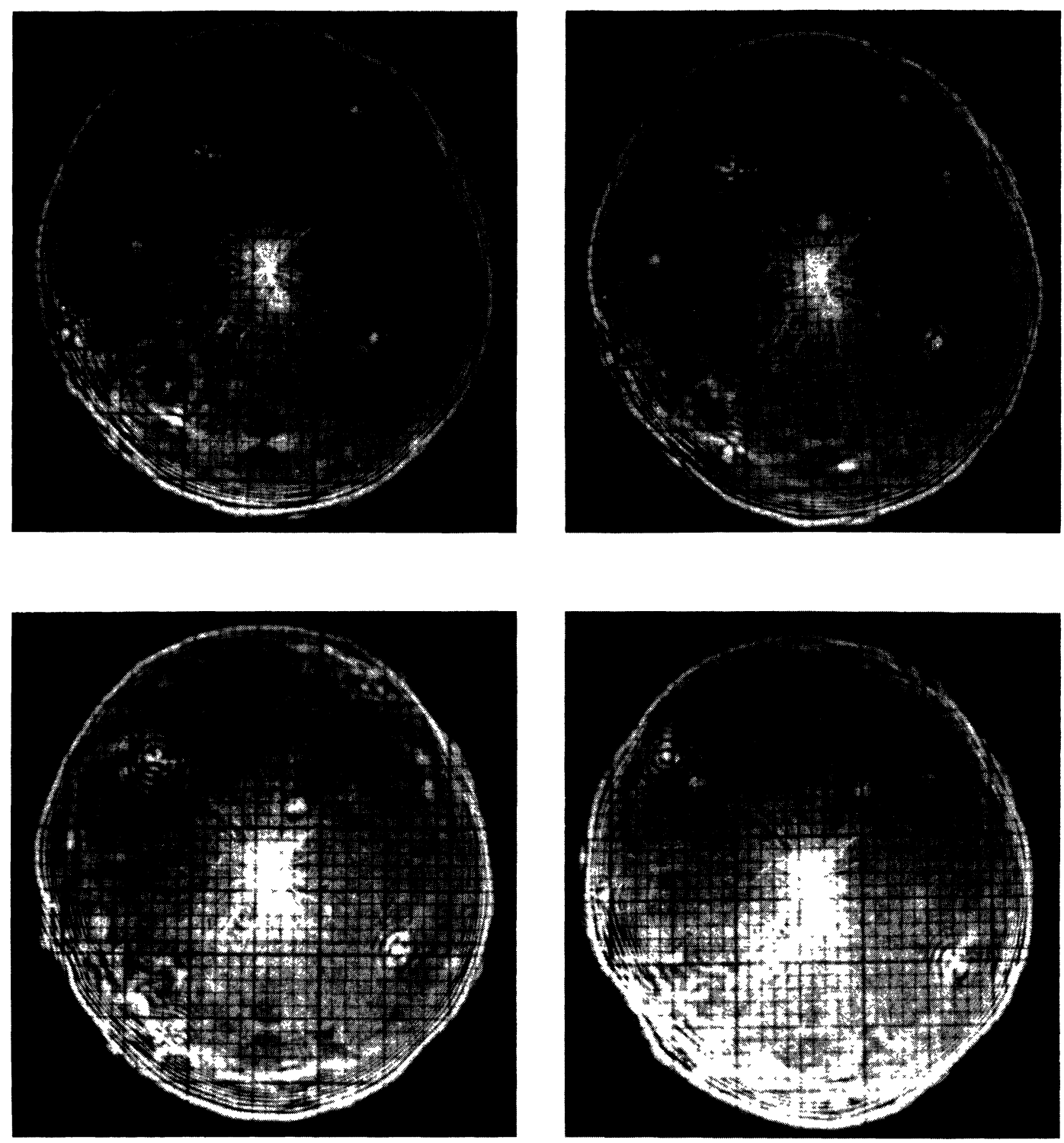

Fig. 5. - Photographs of the light field reflected from the deformed liquid surface at longer heating times. The spots are diffraction patterns of bubbles born at the central hot-point. The bubbles follow radial trajectories as a result of the centrifugal surface-tension gradient.

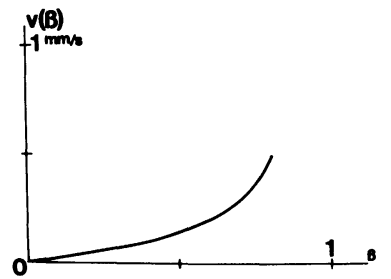

a

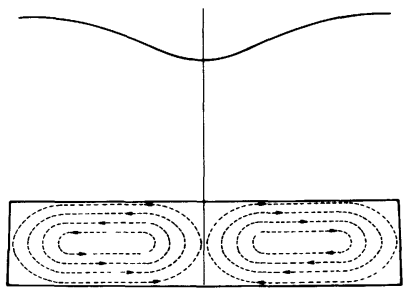

b

Fig. 6. - a) Radial speed of a bubble as a function of its position. This graph may be compared with figure $1 b$. b) Pictorial representation of the flow pattern in the vessel.

conclusion and a theoretical analysis of the nonstationary stage is lacking. Also from an experimental viewpoint this initial transient stage is practically unexplored : our photographic records of the surface profile were performed with a time-resolution of $0.25 \mathrm{~s}$, and the velocity distribution is only known for long heating times $(t>1 \mathrm{~min}$.).

e) An implicit hypothesis in the preceding analysis is $\eta=$ constant, while in our experiments we have $\partial \eta / \partial T \cong 0.1$ poise $/{ }^{\circ} \mathrm{C}$ at $25^{\circ} \mathrm{C}$. Consideration of this fact may require the integration of Navier-Stokes equation with temperature-dependent $\rho, \alpha$, and $\eta$.

$f$ ) Equation (1) is valid when conduction is the only heat-transmission mechanism. Consideration of heat-convection may be necessary in the case of long heating-times, when the flow pattern is fully developed. 
Acknowledgments. - The author thanks enligh- acknowledges also support of the Venezuelan Agencies tening comments formulated by Prof.C. Froehly (Univ. FONINVES and CONICIT and of the Ministère des de Limoges, France) and by anonymous referees. He Affaires Etrangères (France).

\section{References}

[1] Bénard, H., Ann. Chim. Phys. 23 (1901) 62.

[2] Berg, J. C., Acrivos, A. and Boudiart, M., Adv. Chem. Eng. 6 (1966) 61.

[3] Normand, C., Pomeau, Y. and Velarde, M. G., Rev. Mod. Phys. 49 (1977) 581.

[4] CoHen, M. I. in Laser Handbook, F. T. Arecchi and E. O. Dubois, Eds. (North Holland, Amsterdam) 1972, p. $1586-1587$.

[5] LANDAU, L. and Lifschitz, E., Mécanique des Fluides (Editions MIR, Moscow) 1971, p. 296-297.

[6] DA Costa, G., Thèse de Doctorat ès Sciences Physiques (Univ. de Paris-VI) 1982.

[7] Calatroni, J. and DA Costa, G., «Interferometric Determination of the Surface Profile of a Liquid Heated by a Laser Beam ", Opt. Commun. 42 (1982) 5 . 